\title{
The individual dynamics of wage income in France during the crisis
}

\author{
Pierre Pora*, Lionel Wilner**
}

\begin{abstract}
The uncertain nature of future income limits the ability of agents to smooth their consumption over time. Variation in this uncertainty can thus bring about variation in well-being. We study the evolutions of the uncertainty on wage income in France before and over the course of the crisis of 2008 drawing on longitudinal administrative data. Using a non-parametric method, we estimate the magnitude and form of this uncertainty and show that they depend on past wage income. This uncertainty is broken down into wage and working time, and according to the mobility of the wage earners. During the crisis, the magnitude of this uncertainty on future wage income increases slightly, and its downward asymmetry is stronger at both ends of the wage income scale: with this uncertainty, unfavourable evolutions have a bigger impact during the crisis than in the preceding period. This is explained by a heightened probability of unfavourable individual evolutions in terms of working time for the lowest-paid workers, and in terms of wage for the highest-paid. Mobility is more frequent during the crisis but the uncertainty associated with it is lower than over the preceding years.
\end{abstract}

JEL Classification: E24, J24, J31.

Keywords: wage income, non-Gaussian shocks, non-parametric estimation, skewness, kurtosis

Reminder:

The opinions and analyses in this article

are those of the author(s)

and do not

necessarily reflect

their institution's

or Insee's views.
*Insee and Crest (pierre.pora@insee.fr)

**Ensae and Crest (lionel.wilner@ensae.fr) 
$\mathbf{T}$ he magnitude and evolution of income inequalities today takes up a central place in the public debate (Piketty, 2013). These inequalities can be sensitive to the business cycle. Thus, in France, for wage income, that is the sum of all wages received by an individual over the course of one year, the financial crisis of 2008 (the "Great Recession") brings a halt to the downward trend of inequalities (Coudin et al., 2014): wage income inequalities in the lower half of the distribution are greater between 2009 and 2011 than between 2007 and 2008. The concentration of the mass of wages in the $1 \%$ of the highest wage earners shows a reverse trend: it decreases from 2007 to 2008. However, the measurement of inequalities based on cross-section data alone may turn out to be insufficient: increasing inequalities might indicate that the incomes of different individuals diverge permanently but it is also possible that the individuals are confronted with temporary income variations that are more difficult to foresee, in other words that the uncertainty on their future incomes grows.

These two possibilities have different repercussions on the inequalities in terms of consumption (Blundell \& Preston, 1998; Pistolesi, 2014). Great uncertainty on future incomes thus limits the ability of agents to smooth their consumption over time, and can incite them to save more. It can also affect their behaviour on the labour market, for example by leading them to increase their labour supply (Flodén, 2006). This uncertainty is not necessarily the same for all individuals and disparities between individuals can themselves bring about inequalities in terms of well-being. The uncertainty may vary, in terms of magnitude or asymmetry, not only from one individual to the next but also over the course of the business cycle (Mankiw, 1986; Constantinides \& Duffie, 1996), even if empirical studies do not always converge on the direction of this variation.

This article examines the dynamics of wage income around the crisis of 2008. During this crisis, wage income slows down: average wage income (in real terms) for all wage earners progresses by $0.2 \%$ per year on average between 2007 and 2012, against $0.6 \%$ per year from 2002 to 2007 (Coudin et al., 2014). However, these variations in average wage income do not necessarily reflect the individual evolutions of wage income over the period, since they also incorporate the effect of workers entering and leaving paid employment. We compare the individual dynamics of wage income between the period 2005-2006 - that being the individual evolutions of wage income over 2005-2006 and 2006-2007 - and the period 2008-2011 - that being the individual evolutions of wage income 2008-2009 to 2011-2012. Between these two periods, the individual dynamics may differ in two respects. On the one hand, over the course of the crisis, wage earners may see wage income increases that are faster or slower than over the course of the years which precede it. This variation is not necessarily the same with respect to differences in individuals' past wage income and their observable characteristics. This has an impact on inequalities, and may reflect a relatively permanent and foreseeable divergence of their wage incomes. On the other hand, the individual dynamics of wage income may also be more or less uncertain, and therefore more or less difficult to anticipate for the wage earners. This uncertainty might too evolve over the course of the crisis, and in a variable way in accordance with the wage earners.

After a review of the international literature on the variations of uncertainty on future wage income with the business cycle, we describe the difficulties in the estimation of the uncertainty on future wage income, then we analyse the individual dynamics of wage income in France. For this, we apply the non-parametric method proposed by Guvenen et al. (2014) on a French panel data set, based on the panel of annual declarations of social data (Déclarations anuelles de données sociales - DADS) called the "all wage earners" panel which is paired with the permanent demographic sample (Échantillon démographique permanent - EDP) produced by Insee (Box 1). This approach relies on a precise division, and focuses on the shape parameters of the distribution of wage income evolutions. It would therefore be difficult to implement over survey data. Conversely, the considerable size of the sample of the "all wage earners" $D A D S$ panel (about two million wage earners aged from 20 to 60 for each year in the period studied) and the good quality of data allow for the use of this method. We then compare the dynamics of wage income over the course of the crisis to the dynamics of wages in previous years, then the evolutions within a same firm in relation to those which are associated with mobility between two firms. 
Box 1 - Data, coverage and definitions

\section{The "all wage earners" DADS panel and its pairing with the EDP}

The "all wage earners" panel of annual declarations of social data [déclarations annuelles de données sociales (DADS)] is a longitudinal file extracted from several administrative sources. These administrative sources are the annual declarations of social data (DADS), the pay files of government agents, and the information system of public servants (Système d'information des agents des services publics - SIASP). Existing since 1967 in the private sector, the all wage earners panel covers the whole scope of paid employment since 1988, namely the private sector and public services (state public service, regional public service and public hospital service). It follows periods of employment, the characteristics of the employers and employees in a sample of 1/12th of the population of wage earners since 2002.

For each position occupied in the sample by an employee in a given company over the course of one year, the all wage earners panel gives information on net remuneration paid by the employer, the number of days of remuneration in the year, as well as the gender, year of birth and employment status of the wage earner. The number of hours remunerated is available for the wage earners in the private sector, in regional public service and public hospital service over the whole period studied. It gives an overview for wage earners in state public service from 2009 onwards only. We do have, however, for these wage earners, a duration of pay converted into full-time equivalent up until 2008.

The biographical file taken from the permanent demographic sample (Échantillon démographique permanent $(E D P)$, paired with the DADS panel, also gives an overview on the degree level of a part of the wage earners present in the sample, taken from data from annual population censuses and annual census surveys.

\section{Coverage}

The results presented in this article concern wage earners aged from 20 to 60 years, working in metropolitan France between 2002 and 2012. Agricultural wage earners, apprentices and trainees, and wages directly paid by households are not taken into account.

In order to limit the study to wage earners who are relatively well established on the labour market, the coverage is restricted to the wage earners who earn more than an eighth of the yearly minimum wage. The main stylised facts highlighted in this article are robust with regards to the choice of threshold (a sixteenth, an eighth or a quarter of the yearly minimum wage). We make the choice to keep the data relating to extremely highly wage incomes unmodified. Our main results are also robust thanks to a winsorizing for each quantile in the way of 0.9999 of yearly wage income, that being when the wage income of the $0.01 \%$ highest-paid wage earners is put at the same level of this quantile.

The method employed requires restricting the data to a portion of relatively stable wage earners who have been in employment for several consecutive years. More specifically, a wage earner goes into the field of relatively stable wage earners for the year $t$ if they receive a wage higher than an eighth of the minimum wage in $t$, $t+1, t-1$, and two years at least between $t-5$ and $t-2$. Due to the left censoring in 2002, this condition is slightly more demanding at the start of period - 2005 and 2006 - than from 2007 onwards: the share of relatively stable wage earners in the starting sample increases automatically (see Figure). We show, however, that in terms of increased female participation, age distribution, sector, socioprofessional category and degree, and in terms of wages and wage income, this selection differs little between 2005-2006 and 2008-2011 (see annex, Tables $\mathrm{A} 1$ and $\mathrm{A} 2$ ).

\section{Figure \\ Number of observations per year and selection of the sample of relatively stable wage earners}

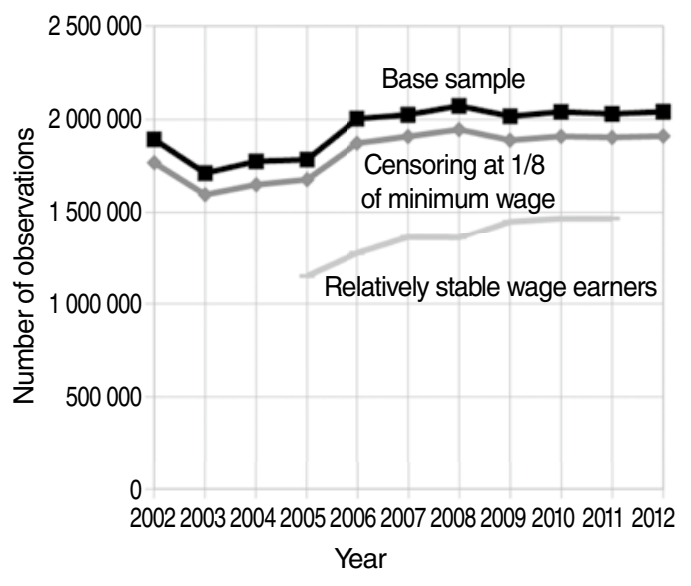

Coverage: Metropolitan France from 2002 to 2012, all wage earners except agricultural wage earners and apprentices and trainees, except wages directly paid by households.

Sources: Insee, "all wage earners" DADS Panel

\section{Wage income}

The variable of interest is real yearly wage income. It incorporates net remunerations (that being after social security contributions, CSG [general welfare contributions] and CRDS [social debt repayment contributions]) taken from paid work undertaken by a same individual over the course of a given year. These remunerations may be paid by different employers. Wage income is therefore defined only for individuals who have been in paid employment over the course of a year. It does not take into account unemployment benefits.

It integrates two factors: hourly wage, the price of one unit of paid work, and the volume of paid work undertaken over the course of a year. This volume reflects the wage earner's quota of working time (full-time, part-time) and the number of days they have worked over the course of the year (periods of employment). It therefore integrates a part of the risk linked to non-employment, notably for the wage earners in the private sector. 
Box 1 (suite)

\section{Work volume}

We use the data of the duration of wage-earning convertible into full-time equivalent, available for wage earners in state public service up until 2008, and of the number of hours remunerated, available for the rest of the wage earners over the period studied, and for wage earners in state public service from 2009 onwards in order to build a yearly full-time equivalent working time I of between 0 and 1 . The use of the variable / supposes that the duration of wage-earning convertible into full-time equivalent and the number of hours can be manipulated to make them comparable and relatively homogeneous over time. It therefore brings one to disregard the break in the series that arose in 2009 in state public service. Each year of the period studied, the calculation of an FTE work volume is possible for $99.9 \%$ of the relatively stable wage earners. The construction of this full-time equivalent working time is detailed in the online complement C3.

\section{The business cycle and uncertainty on future wage income in the literature}

\section{An increased uncertainty during recessions?}

Many studies on the United States agree on the counter-cyclical nature of the magnitude of uncertainty on future wage income. Gottschalk et al. (1994) show that the variance of the temporary evolutions of wage income increases notably between 1974 and 1975 with the $1^{\text {st }}$ petrol shock, and between 1980 and 1983 during the two episodes of recession which came at the start of the 1980s. In addition to these fluctuations with the business cycle, this variance shows a long-term upward trend over the 1970s and 1980s. Moffitt and Gottshalk (2002), drawing on another modelling of the individual dynamics of wage income, obtain the same result for the period 1980-1983. Over the period 1967-1991, Haider (2001) also documents an increase of the extent of uncertainty during recessions, which is essentially linked to instability in terms of working time, with hourly wage volatility hardly varying at all over the course of the period studied. Finally, studying the period 1968-1993, Storesletten et al. (2004) also highlight an uncertainty whose magnitude, increasing by $75 \%$ between periods of growth and periods of recession, is very counter-cyclical.

Most of these works relates to measures of moments of order 2 of the evolutions of wage income. Some use very simple methods which do not take into account wage earners' heterogeneity; others call upon more sophisticated specifications, which assume conditional log-normality of the variations of wage income, and therefore neglect their asymmetry. Contrastingly, Guvenen et al. (2014) use a method which does not presuppose the log-normality of wage income evolutions. This leads them to reject the hypothesis of a counter-cyclical variance of the evolutions of wage income in the US, in particular between 2007 and 2010. They show that the hypothesis of counter-cyclical variance, that is a conditional variance of the evolutions of wage income that increases during recessions, may result in part from an underestimation of how heterogeneous variations with the business cycle of these individual wage income evolutions are across the distribution of past wage income. In other words, it is not that the evolutions of wage income are more dissimilar within very similar groups of wage earners over the course of recessions, but rather that over the course of recessions the evolutions of wage income are more dissimilar between groups of wage earners which are already dissimilar, and, notably, between wage earners located at the extremes of the distribution of past wage income and those not. The authors show that over the period 2007-2010, the loss of wage income is concentrated on average over the lowest-paid wage earners in the past, and over the very high wage incomes. Moreover, over the course of the recessions that they study, and for all levels of past wage income the individual evolutions of wage income are more downwardly asymmetrical: the share of less favourable evolutions in the dispersion increases whereas that of the most favourable evolutions decreases.

For a more recent period, Dynan et al. (2012), still over American data, by using an aggregated measurement of the variance of the evolutions of wage income, show an increase in the magnitude of uncertainty on future wage income over the years which precede the 2008 crisis, without however explicitly linking it to the business cycle. 


\section{Variations over a long period of uncertainty on future wage income in Europe}

A few studies treat the evolutions of the volatility of wage income in European countries, using methods that assume conditional log-normality of the individual evolutions of wage income. For the United Kingdom, Ramos (2003) highlights a possible increase of the volatility of the transitory evolutions of wage income between 1991 and 1999. For Italy, Cappellari (2003) rather links the rise of inequalities between the 1970 s and 1980 s to a long-term component; however, the youngest cohorts could be characterised by a greater uncertainty of the transitory evolutions of wage income. In France, Ceci-Renaud et al. (2014) highlight the evolutions of wage income volatility over a long period: it is approximately constant from the end of the 1960s to the early 1980s. It then increases before decreasing throughout the 1990s. Before the crisis, it decreases to reach its local minimum in 2008. It then increases in 2009 , at the start of the crisis.

\section{Wage income uncertainty can be heterogeneous between wage earners}

The temporal variations of the uncertainty on future wage income do not affect wage earners in a uniform manner. So, by using a method which allows them to distinguish, when making choices of education, between an uncertain component and a component which is foreseeable by the agents, mixing observed and unobserved heterogeneity, Cunha and Heckman (2007) link the rise in income inequalities at the end of the $20^{\text {th }}$ century in the US to an increase in the uncertainty and the heterogeneity of wage earners over the period. The rise of uncertainty explains a large part of the increase in inequalities among the least-skilled wage earners, while its weight is much lower among the most-skilled wage earners.

Britton et al. (2015) focus on the disparities of the evolutions of wage income according to the education level during the crisis of 2008. To do this they draw on survey data and administrative data, and highlight large losses of wage income when cohort effects are controlled for. These losses are much greater for non-graduates than for graduates, while the average differences in terms of wage income level are not very large, which would reflect a protective effect of degrees.
Finally, Ayllón and Ramos (2015) conduct a comparative work on the evolution of wage income instability among young people (17 to 29 years old) in the European Union during the 2008 crisis. Despite differences between countries, their results, obtained with relatively simple methods applied to the EU-SILC survey data, show for these young people an increase in wage income volatility, that breaks the downward trend of the years preceding the crisis. This increase is not uniform depending on age, sex and degree level, and its magnitude is not the same across all countries.

\section{Measuring uncertainty on future wage income}

From the point of view of individuals, uncertainty on future wage income depends on the information available to each of them. A large part of this information is however not observed directly in the data. Representing this uncertainty as the distribution of probability of future incomes (conditional to the observable and unobservable characteristics of individuals) shall be therefore based on a modeling. The most current ones distinguish between transitory evolutions and long-term evolutions on the one hand, and heterogeneity between individuals (observed and unobserved) and uncertainty on the other hand. This modelling of wage income dynamics relies in general on an assumption of conditional log-normality of the evolutions of wage income (Moffitt \& Gottschalk, 2002, 2011; Baker \& Solon, 2003; Low et al., 2010; Altonji et al., 2013; Magnac et al., 2017; Ceci-Renaud et al., 2014).

The log-normality assumption leads to focus the analysis on the dispersion of wage income evolutions, measured notably by the variance, and to neglect the role of the shape parameters of the distribution, in particular the asymmetry and weight of extreme shocks, measured for example by the moments of order 3 and 4 (consistent with the log-normality hypothesis). On the contrary, the asymmetry and weight of the tails of distribution in the evolutions of wage income make up a central point for Guvenen et al. (2016). By offering an original non-parametric approach and by exploiting very rich administrative data, they highlight the highly asymmetrical downward shape of wage income evolutions, the significance of extreme individual wage income variations, which leads them to reject the assumption of log-normality 
of the distribution of wage income evolutions. They also document a strong non-linearity of the dependence of future evolutions on past wage income levels. They finally show that the hypothesis of log-normality can lead to a significant underestimation of the cost of income shocks in terms of well-being. There are few other approaches relaxing the log-normality hypothesis (Bonhomme \& Robin, 2009; Arellano et al., 2017).

The first step in estimating the uncertainty on future wage income consists of setting the temporal scale of this uncertainty. Here we make the choice to focus only on wage income uncertainty in the year immediately following, that is the uncertainty on wage income of year $t+1$ for a wage earner observed in year $t$. We also consider that the wage income of year $t$ is known with certainty; the uncertainty therefore comes from the variation of wage income between $t$ and $t+1$. Finally, we equate this uncertainty on future wage income with the distribution of probability of the yearly variations of the wage income logarithm: $\delta \tilde{y}_{i, t}=\tilde{y}_{i, t+1}-\tilde{y}_{i t}$, where $\tilde{y}_{i t}$ represents the logarithm of wage income individual $i$ in year $t$, for each year of the period studied.

Following on from Guvenen et al. (2014), we focus on four different properties of this distribution. The first is the level of these variations, typically measured by the average or quantiles. The second relates to the dispersion of these variations: it can be measured by the variance or the D9-D1 interdecile range. We consider that it estimates the magnitude of the uncertainty on future wage income. ${ }^{1}$

The two other properties relate to the shape of this distribution. Firstly, its asymmetry, that is the relative weight of high and low evolutions in the dispersion; it is measured by the skewness, or by a measure based on quantiles, Kelley's Measure of Skewness (Kelley, 1947) (see Box 2). A decline in skewness or in Kelley's Measure of Skewness during recessions, that is, in this case, a significant downward asymmetry, means that the uncertainty on less favourable evolutions increases more than the uncertainty on more favourable evolutions. In other words, very negative shocks become relatively more probable than very positive shocks, which the measurements of level and dispersion do not account for. These disastrous evolutions may have very different consequences from those of

1. This conditional distribution may also incorporate chosen and anticipated evolutions which are not interpreted as an uncertainty. negative evolutions of a smaller scale, notably in terms of well-being. It is therefore important to detect a potential variation of their frequency. A rise in the probability of very negative shocks seems to be a fairly general characteristic of recessions, not only from the point of view of wage earners, but also for firms or macroeconomic aggregates (Salgado et al., 2016).

Then, the weight of the tails of distribution, that being the relative importance of rare events in the dispersion, estimated by the kurtosis, or a measure based on quantiles, Crow-Siddiqui Kurtosis (Crow \& Siddiqui, 1967). The measures of the level and dispersion of individual evolutions of wage income do not distinguish between relatively current evolutions of weak magnitude, and between rarer and extreme evolutions. It is, however, plausible that the long-term consequences of these extreme shocks, whether they are positive or negative, differ from those of less significant shocks. So, a given dispersion of individual evolutions of wage income, can have different effects on the behaviour of individuals, depending on whether it is associated or not with a heightened weight of rare events, for example in terms of consumption and saving (Guvenen et al., 2016). Under the (log)normality hypothesis, the shape parameters - asymmetry or the weight of distribution tails - are presumed to be constant.

Described as the distribution of probability of the individual variations of wage income between two successive years, uncertainty on future wage income depends largely on the information available: the uncertainty must be perceived as a conditional distribution of probability. All of the information to which a given individual has access in $t$ is of course not available: it is therefore necessary to model it in order to approach it. In the preceding case, we consider that all the information available is brought by the wage income of recent years. We then divide up the heterogeneity of the yearly evolutions of wage income considered over all of the individuals according to two factors. On the one hand, the individual yearly evolutions of wage income depend on the individuals' past level of wage income. This form of heterogeneity is taken into account by grouping together the wage earners who have had a comparable wage income in recent years. On the other hand, in each of these groups of wage earners with comparable past wage income, the evolutions of wage income are variable, which is measured by focusing on the distribution of evolutions of wage income for each of them. It is this 
conditional distribution that we interpret as a reflection of this uncertainty.

A significant part of the yearly evolution of an individual's wage income is linked to their age. To build the groups of wage earners with recent-past wage income, the average effect of age must be neutralised in order to make the wage income of wage earners of different ages comparable. We normalise the wage income by negating this

\section{Box 2 - Method}

\section{Breakdown of the yearly evolutions of wage income}

We use the method developed by Guvenen et al. (2014), by applying it to the yearly evolutions, and not to the five-yearly evolutions, of wage income.

For each wage earner $i$, let's consider $\tilde{y}_{i t}$ the logarithm of their wage income of the year $t$, and ${ }^{i, t} Y_{\text {, their wage }}$ income. We focus particularly on the yearly evolutions of wage income $\delta \tilde{y}_{i, t}=\tilde{y}_{i, t+1}-\tilde{y}_{i, t}$, whose distribution we wish to estimate conditional to the characteristics of $i$, and notably to their past wage income.

We wish to highlight a potential variation of this distribution over time, notably by distinguishing between the period which precedes the crisis and the one that succeeds it. On average over the course of professional life, wage income increases with age, but its progression is less and less quick. So, if age is not monitored, and if for example the crisis led young people to delay their entry into paid employment, such that the average age of the population studied increases between the period which precedes the crisis and the one which succeeds it, we would be brought to the conclusion that the evolutions of wage income became less favourable with the crisis, without the dynamics of wage income being affected as such. To avoid this, we normalise wage income by eliminating the average effect of age. This does not however take into account potential composition effects linked to age over the dispersion or the form of the distribution of the individual evolutions of wage income.

More specifically, we define the average effect of age $\beta_{a}$ that we wish to take away from wage income by:

$$
\left\{\begin{array}{c}
\tilde{y}_{i t}=\sum_{a} \beta_{a} \mathbf{1}\left[\text { age }_{i t}=a\right]+\sum_{T} \gamma_{T} \mathbf{1}\left[\text { birth }_{i}=T\right]+\varepsilon_{i t} \\
\mathbf{E}\left[\varepsilon_{i t} \mid \text { age }_{i t}, \text { birth }_{i}\right]=0
\end{array}\right.
$$

We estimate the coefficient $\beta$ by conducting a regression analysis on all the wage earners of metropolitan France aged from 20 to 60 years between 2002 and 2012 who receive more than an eighth of the yearly minimum wage.

The results of the estimation of $\beta$ fulfil the expectations regarding the average effect of the life cycle on wage income: rapid progression at the start which corresponds to entry onto the labour market, then a slower increase under the effect of the gradual accumulation of experience, a slight decrease at the end of the career which reflects departures from paid employment which occur over the course of the year (see Figure).

The estimation of $\beta$ allows for the introduction of normalised wage income $\delta y_{i, t}=\tilde{y}_{i, t}-\hat{\beta}_{a}$. We are particularly interested in the individual evolutions of normalised wage income: $\delta \tilde{y}_{i, t}=\tilde{y}_{i, t+1}-\tilde{y}_{i, t}$ or $\delta y_{i, t}=\hat{\varepsilon}_{i, t+1}-\hat{\varepsilon}_{i, t}$. We introduce again the past normalised wage income of the relatively stable wage earners.

$$
Y_{i t}^{a n t}=\frac{1}{\sum_{\tau=t-5}^{\tau=t-1} \sum_{a} \exp \left(\hat{\beta}_{a}\right) \mathbf{1}\left[\hat{a} g e_{i \tau}=a\right]} \sum_{\tau=t-5}^{\tau=t-1} \tilde{y}_{i \tau}
$$

By using the results from the estimation of $\hat{\beta}_{a}$, we consider $y_{i, \text { et }} Y_{i t}^{\text {ant }}$ as representing on the one hand the logarithm of wage income in the year $t$, from which the average progression of wage income over the course of a life cycle has been taken away, and on the other hand average wage income over the 3 to 5 preceding years, neutralised by the average effect of age.

We then order all the relatively stable wage earners in paid employment according to their past normalised wage income $Y_{i t}^{\text {ant }}$ to build a scale of past wage income net of the average effects of age. More specifically, we associate with the wage earner $i$ in the year $t$ a rank $\alpha$. of between 0 and 99 such as $Y_{i t}^{\text {ant }}$ being between the percentile of rank $\alpha_{i t}$ and the percentile of rank $\alpha_{i t}+1$ of the distribution of $Y^{\text {it }}$.

\section{Figure \\ Average effect of age on the life cycle calculated using the coefficient $\boldsymbol{\beta}_{a}$}

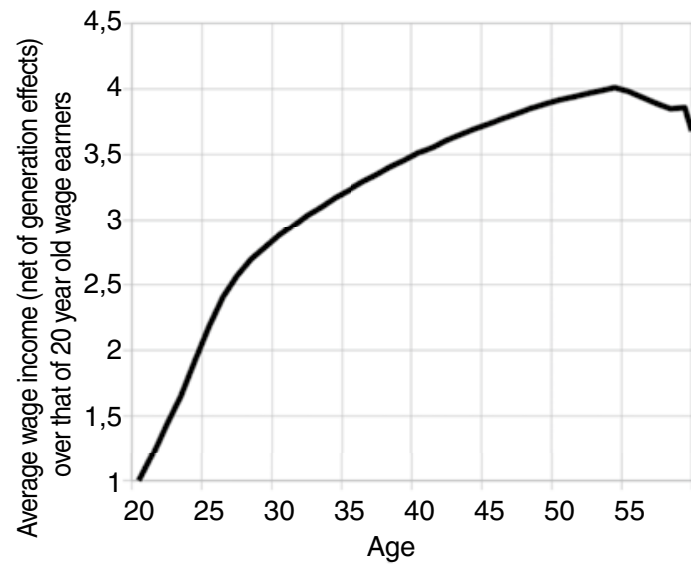

Reading note: average wage income net of the generation effects valued at 30 years old is 2.9 times what it should be at 20 years old Coverage: Metropolitan France from 2002 to 2012, all wage earners having earned $1 / 8$ of yearly minimum wage, except agricultural wage earners and apprentices and trainees, except wages directly paid by households.

Source: Insee, "all wage earners" DADS Panel 
Box 2 (suite)

\section{Measures of dispersion, of asymmetry and of weight of tails of distribution}

We measure the dispersion of the evolutions of wage income $\delta y$ conditional to the rank, alternatively by the standard deviation and the D9-D1 interdecile spread.

Skewness is a measure of asymmetry which corresponds to the moment of order 3 of the reduced centred variable. We use an unbiased estimator:

$$
\text { Skewness }=\frac{n}{(n-1)(n-2)} \sum_{i=1}^{n}\left(\frac{x_{i}-\bar{x}}{\hat{\sigma}}\right)^{3}
$$

Kelley's Measure of Skewness is a measure of the asymmetry of distribution alternative to skewness (Kelley, 1947). It measures the parts relating to the D9-D1 interdecile spread explained by interdecile spreads D5-D1 and D9-D5:

$$
\text { Kelley's Skewness }=\frac{D 9+D 1-D 5}{D 9-D 1}
$$

Kurtosis measures the weight of the tails of distribution from the moment of order 4 of the reduced centred variable. We use an unbiased estimator which is equal to 0 for a Gaussian distribution:

Kurtosis $=\frac{n(n+1)}{(n-1)(n-2)(n-3)} \sum_{i=1}^{n}\left(\frac{x_{i}-\bar{x}}{\hat{\sigma}}\right)^{4}-\frac{3(n-1)^{2}}{(n-2)(n-3)}$

The Crow-Siddiqui Kurtosis is a measure of the weight of the tails of distribution alternative to kurtosis (Crow \& Siddiqui, 1967). It is defined by:

Crow - Siddiqui Kurtosis $=\frac{P 97.5-P 2.5}{P 75-P 25}$

where $P x$ represents the quantile of order $x / 100$ of the distribution. It is consistent at 2.91 in the case of a Gaussian distribution. The usefulness of the measures based on quantiles stands to their robustness with regards to extreme values.

\section{Bootstrap}

In order to ensure that our results are significant, we estimate a confidence interval at $95 \%$ by bootstrap. In order to limit the calculation time, we conduct this estimation point by point along the wage scale, and not over the whole procedure. This comes to the consideration that the attribution of rank $a$ is made without error, and therefore the term of variance linked to the attribution of ranks is neglected. This term is even greater since the density of the percentiles of the distribution of normalised wage income is small - for example for the highest wage incomes - and since the statistic of interest varies greatly with the rank. We limit ourselves in the end to 100 replications.

In the case of the average, the confidence interval thus estimated is comparable to that which is estimated using the variance, under the same hypothesis of perfect attribution of ranks.

\section{Normalisation of wages and working time}

By using the data of (the logarithm of) wage income $Y$ and of full-time equivalent work time $L$, we construct a full-time equivalent wage $W=Y / L$. Then, we use the logarithm of these quantities (written in lower case).

To focus on the yearly evolutions of full-time equivalent work time and wages, we then treat $w$ and $l$ independently of each other, in the same way as $y$ :

$$
\begin{aligned}
& \tilde{w}_{i t}=\sum_{a} \lambda_{a} 1\left[\text { age }_{i t}=a\right]+\sum_{T} \mu_{T} 1\left[\text { birth }_{i}=T\right]+v_{i t} \\
& \tilde{l}_{i t}=\sum_{a} \theta_{a} 1\left[\text { age }_{i t}=a\right]+\sum_{T} \kappa_{T} 1\left[\text { birth }_{i}=T\right]+\eta_{i t}
\end{aligned}
$$

We conduct the estimation of each of these regressions separately. The normalised full-time equivalent wage is defined as $w_{i t}=\tilde{w}_{i t}-\hat{\lambda}_{a}$ and the normalised work volume as $l_{i t}=l_{i t}-\theta_{a}$. We introduce the yearly evolutions of full-time equivalent wages and work volume $\delta_{w}$ and $\delta_{l}$, whose distribution we study conditional to $\alpha$.

This approach therefore supposes the treatment of wages and working time as two factors that are independent of each other, and therefore that the possible correlation between the yearly evolutions of work volume and the yearly evolutions of wages is neglected.

\section{Inter-company mobility}

We define more specifically the wage earners who do not undergo inter-company mobility as those who in $t$ and $t+1$ occupy a position of paid employment in one same company identified by its SIREN [Système d'identification du répertoire des entreprises - French company number]. Conversely, we consider that a wage earner has undergone an inter-company move when, between $t$ and $t+1$, the main company changed (in terms of its SIREN number), with the main company for a year being defined as the one in which the duration of wage-earning is the longest. So, while the wage earners who do not undergo inter-company moves may not be multi-assets (wage earners), this may be the case for those who do not undergo moves.

\section{Division of periods}

We focus on the evolutions of the distribution of $\delta y$ conditional to $\alpha$ with time. More specifically, we seek to know whether this conditional distribution varied over the course of the crisis, and whether these variations may be characterised in terms of changes of the uncertainty on future wage income. To do this, it is necessary to distinguish between the evolutions that occur over the course of the crisis and those which succeed it.

The data available also play on this choice. In fact, the past normalised wage income $Y^{\text {ant }}$ which is necessary to the definition of $\alpha$, is only defined for the relatively stable wage earners, that being those in paid employment for three years before the year $t$. In other words, by using a sample which starts in 2002, the distribution of $\delta y$ conditional to $\alpha$ can only be estimated from 2005 onwards.

The status of the year 2008, and from that, the evolutions of wage income between 2007 and 2008, is uncertain. This is why we choose not to study it. This leads to the comparison of two periods: 2005-2006 (that being the individual evolutions of wage income 2005-2006 and 2006-2007) and 2008-2011 (that being the individual evolutions of wage income 2008-2009 to 2011-2012). 
effect. We write $\delta y_{i, t}=y_{i, t+1}-y_{i t}$ as the evolution between $t$ and $t+1$ of the wage income of wage earner $i$ net of the average age effect (box 2).

The evolutions of normalised wage income indicate whether a wage earner progresses faster or slower than the average of wage earners of their age. The groups of wage earners whose wage income is comparable are defined by ordering the wage earners according to the average normalised wage income over the five preceding years. The wage earners are thus put into 100 groups of equal size, each one corresponding to a rank $\alpha$ variant of 0 (for the lowest-paid) to 99 (for the highest-paid), on the scale of past wage incomes. This approach requires restricting the study population to wage earners present in paid employment for seven years: the five years over which past normalised wage income is calculated, and the two years between which the evolution of normalised wage income is observed. Our results therefore do not concern the uncertainty on the future wage income of wage earners who have a very fragmented employment path, or who are confronted with long periods of unemployment. They do not take into account uncertainty at the very start of professional life either. Finally, we compare the distribution of $\delta y_{i, t}$ conditional to $\alpha$ between the period 2005-2006 - therefore the individual evolutions of wage income 2005-2006 and 2006-2007 - and the period 2008-2011 - that is the evolutions 2008-2009 to 2011-2012.

\section{Wage income evolutions: on average more favourable at both ends of the distribution of past wage income, but more dispersed}

Over the whole period 2005-2011, and for a large part of the past wage income scale, the average yearly progression decreases as wage income net of the age effect increases (Figure I). In other words, the lowest-paid wage earners in the past face evolutions of wage income that are more favourable than those of their better-paid counterparts (Figure I-A). This can result in part from mean reversion, if there are wage earners who have seen an unfavourable evolution in the past among the lowest-paid wage earners. ${ }^{2}$ This catch-up effect tends to reduce the inequalities

2. To the extent that the years over which on the one hand past normalised wage income ( $t-5$ to $t-1)$ and on the other hand the evolution of normalised wage income ( $t$ to $t+1)$ are estimated are disjointed, and this return towards the norm does not, however, concern very temporary shocks (one sole year with small wage income). within the cohorts. Over the period studied, this is so for $89 \%$ of wage earners whose wage income was lower in the past, particularly for the $20 \%$ of the lowest-paid wage earners. The same remains observed when focusing on the conditional median of the wage income evolutions (Figure I-B).

The magnitude of uncertainty on future wage income, measured by the standard deviation (Figure I-C) and the D9-D1 interdecile range (Figure I-D) conditional of $\delta y_{i, t}$ present a $\mathrm{U}$ shape. In other words, the yearly evolutions of wage income are more dispersed for the lowest-paid wage earners, and to a lesser extent for the very high wage incomes, than for the wage earners whose past wage income takes up an intermediary position in the distribution. By admitting that this dispersion approximates the extent of the uncertainty on future wage income, this uncertainty is greater for the $25 \%$ of wage earners at the lower end of the wage income scale, and the $2 \%$ of the highest-paid wage earners, than for the rest of the wage earners.

For the $5 \%$ to $8 \%$-according to the measurement considered, third moment (Figure I-E) or Kelley's Measure of Skewness (Figure I-F) - of the lowest-paid wage earners, the yearly evolutions of wage income present a slight upward asymmetry. This means that the most significant part of the dispersion of these evolutions is driven by the most favourable evolutions. However, for the rest of the wage earners, this asymmetry is significant and negative, except perhaps for the $1 \%$ highest-paid wage earners (according to the measure chosen). In other words, with the exception of the wage earners at the lower end of the past wage income scale, the considerable yearly variations of wage income are rather downward evolutions.

Extreme yearly variations, finally, have a large impact on the dispersion of wage income evolutions, and this is especially so since at the top end of the past wage income scale. This considerable weight of the tails of distribution in the uncertainty on future wage income, as well as its asymmetry, contradicts the usual log-normality hypothesis. In fact, under the log-normality hypothesis of wage income shocks, the kurtosis is null ${ }^{3}$ and the Crow-Siddiqui Kurtosis is constant and equal to 2.91. Whereas the kurtosis of the yearly variations of wage income increases up until the $96^{\text {th }}$ percentile of the distribution of past normalised wage income (Figure I-G), the

3. Here we estimate the normalised kurtosis. 
Figure I

Individual yearly evolutions of normalised wage income according to the rank in the distribution of past normalised wage income

A. Average

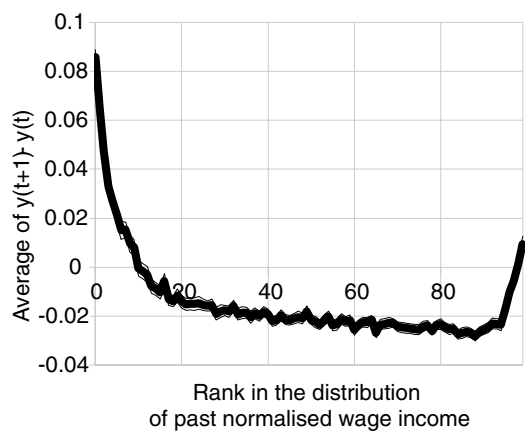

C. Standard deviation

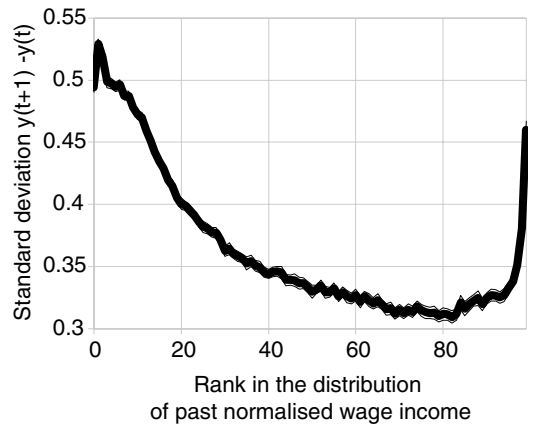

E. Skewness

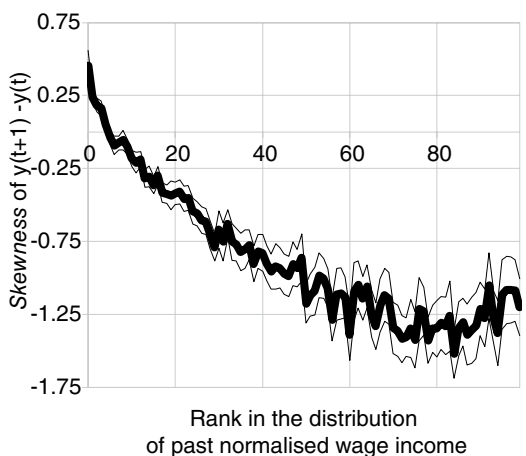

G. Kurtosis

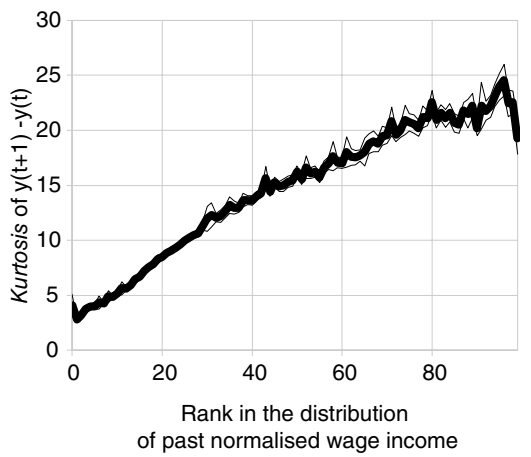

B. Median

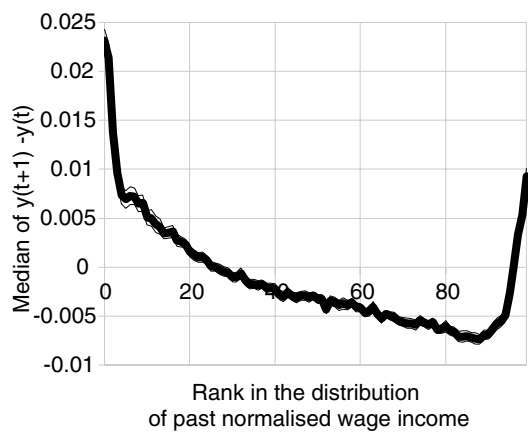

D. Interdecile spread

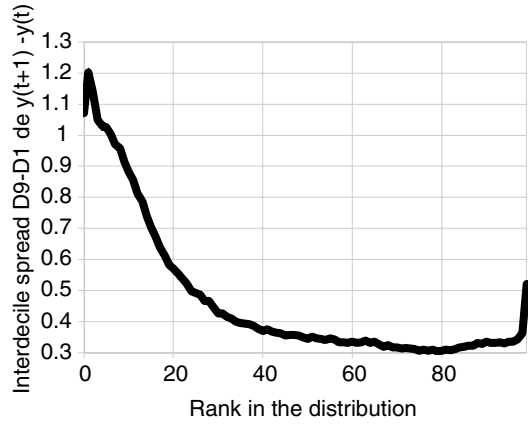

of past normalised wage income

F. Kelley's Skewness

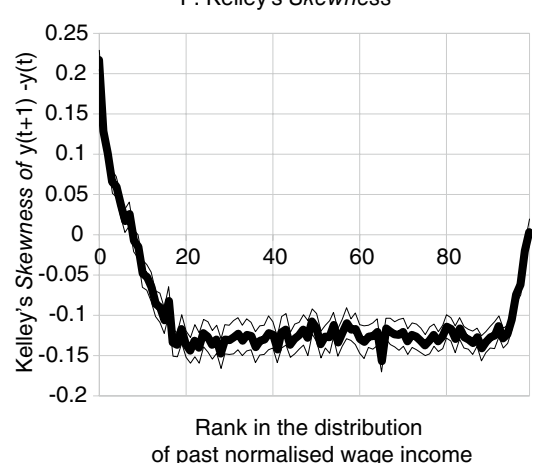

H. Crow-Siddiqui Kurtosis

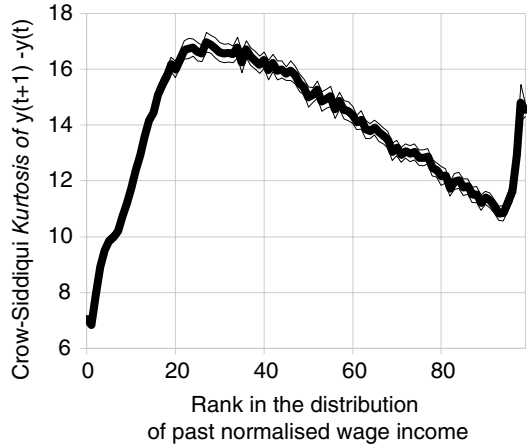

Note: The lower and upper bounds of the confidence intervals at $95 \%$ are represented by thin lines. The confidence intervals are obtained by bootstrap (100 replications) (see box 2)

Reading note: at the 5th rank of the past wage scale, wage earners are confronted with yearly evolutions of wage income higher by 2.1 percentage points on average than the variation of average wage income at their age (graph A). Among them, $50 \%$ see more favourable evolutions of more than 0.6 percentage points than this variation of average wage income (graph B).

Coverage: Metropolitan France between 2005 and 2011, all relatively stable wage earners in paid employment, that being having received $1 / 8$ of minimum wage in $t-1, t$ and $t+1$ and at least two years between $t-5$ and $t-2$, except agricultural wage earners and apprentices and trainees, except wages directly paid by households.

Sources: Insee, "all wage earners" DADS Panel. 
Crow-Siddiqui Kurtosis (Figure I-H) presents a non-monotone profile, which differs from the results obtained for the US (Guvenen et al., 2016). In other words, in France, the weight of rare events in the dispersion of the evolutions of wage income seems to be greater for individuals with very high past wage incomes, or with intermediary levels of past wage income, than for individuals with very low past wage income or, to a lesser extent, to the relatively high levels of the distribution. Contrastingly, in the US, this weight increases with the level of past wage income, with the exception of very high wage incomes. It is possible that this difference stems from differences in the grouping of wage earners between the results of Guvenen et al., (2016) and those which we present. Later on in this article, we privilege measures based on quantiles (median, inter-decile range, Kelley's Measure of Skewness and Crow-Siddiqui Kurtosis) which are more robust to extreme variations than measures based on moments (average, standard deviation, skewness and kurtosis).

\section{The most unfavourable individual evolutions are amplified over the course of the crisis}

Examining the conditional deciles of the individual yearly variations of normalised wage income shows that over the course of the crisis, these individual evolutions became less favourable than they were in the preceding years (Figure II). So, throughout the past income scale, the first decile (D1) and the median (D5) of the individual evolutions of normalised wage income are significantly lower between 2008 and 2011 (and thus for the yearly evolutions from 2008-2009 to 2011-2012) than between 2005 and 2006 (and thus for the yearly evolutions 2005-2006 and 2006-2007). The drop is greatest at the bottom of the wage income scale for the first decile, at the bottom and at the top for the median (Figure III-A). The magnitude of the drop is higher for the first decile than for the median. However, the last conditional decile (D9) only decreases significantly at the extremities of the distribution of past normalised wage income, for the $10 \%$ of lowest-paid wage earners and the $6 \%$ of highest-paid wage earners in the past; it does not vary significantly over the rest of the scale. For these extremities of the wage income scale, the decline of the last conditional decile is greater than that of the median.

This analysis of the conditional deciles already brings valuable information on the evolution of the distribution of individual evolutions of wage income over the course of the crisis. It shows firstly that the dispersion of these individual variations, that we interpret as being characteristic of the extent of the uncertainty on future

Figure II

Deciles of the individual evolutions of normalised wage income before and during the crisis

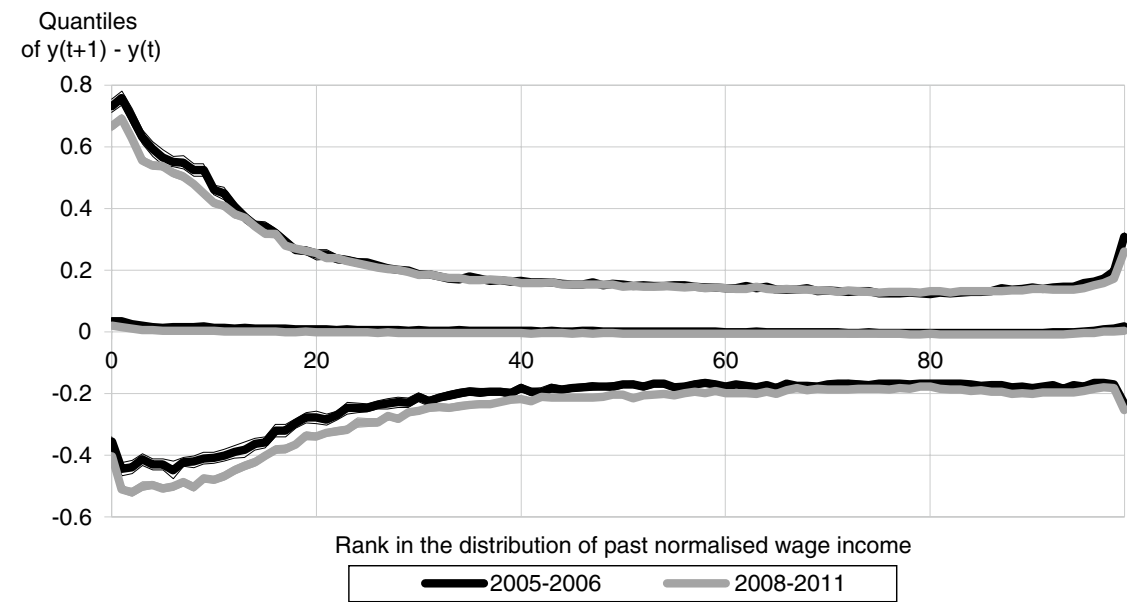

Note: The lower and upper bounds of the confidence intervals at $95 \%$ are represented by thin lines. The confidence intervals are obtained by bootstrap (100 replications) (see box 2).

Reading note: At the 10th rank of the past wage scale, for the years 2005 and $2006,10 \%$ of the wage earners are confronted with yearly evolutions of normalised wage income lower than -0.41 in the logarithm. For the years 2008 to 2011 , at the same level of the scale, $10 \%$ of the wage earners are confronted with evolutions lower than -0.48 in the logarithm.

Coverage: Metropolitan France between 2005 and 2011, all wage earners except agricultural wage earners and apprentices and trainees, except wages directly paid by households.

Sources: Insee, "all wage earners" DADS Panel. 
wage income, increases slightly over the course of the crisis, in particular for the intermediary positions on the past wage income scale. It then indicates that at the lower end of the distribution of past normalised wage income, and to a lesser extent at the higher end, it is the dispersion of the less favourable evolutions which increases, whereas that of the most favourable evolutions decreases. These results are consistent with those obtained on the dispersion, measured by the D9-D1 interdecile range, and on the asymmetry, measured by Kelley's Measure of Skewness which estimates the relative parts of the dispersion in the upper half (D9-D1) and the lower half (D5-D1) in this interdecile range. In fact, over the course of the crisis, the measure of the D9-D1 interdecile range (Figure III-B) shows a slight increase in the part of the distribution from the $16^{\text {th }}$ to the $95^{\text {th }}$ percentile of the past wage income. Additionally, for wage earners located at the extremities of the past wage income scale, Kelley's Measure of Skewness decreases significantly between 2005-2006 and 2008-2011 (Figure III-C), indicating that the weight of the negative evolutions of normalised wage income in the dispersion has become more pronounced over the course of the crisis than in the years before. So, for the wage earners at the bottom and top ends of the past wage income scale, the unfavourable individual variations of wage income play a more important role in the dynamics of wage income over the course

Figure III

Individual yearly evolutions of normalised wage income before and during the crisis

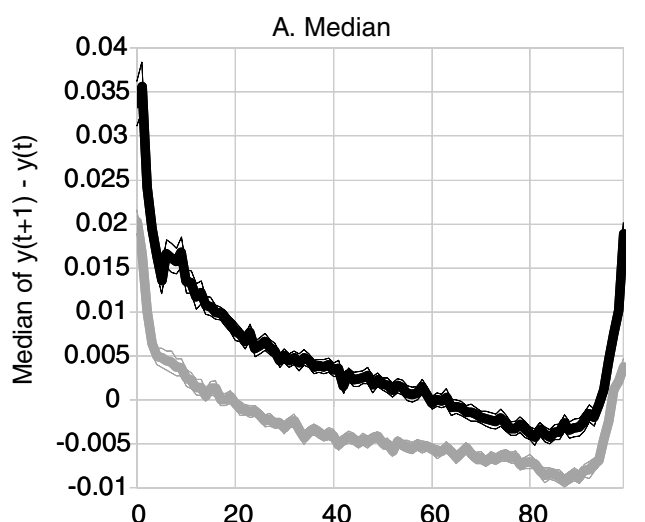

Rank in the distribution of past normalised wage income

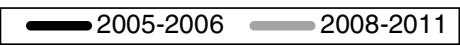

C. Kelley's Skewness

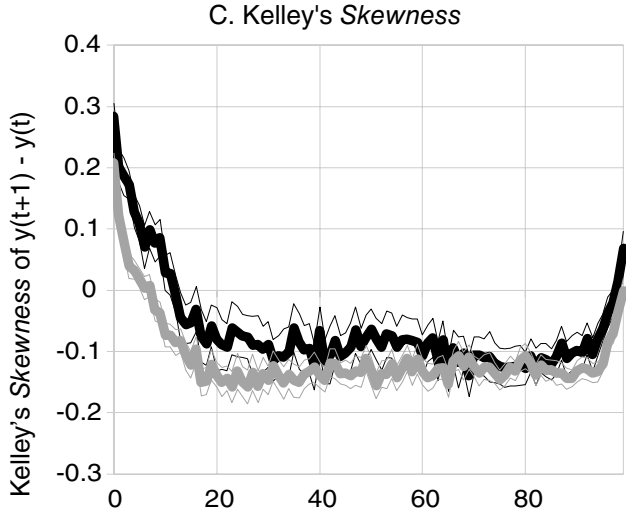

Rank in the distribution of past normalised wage income $\stackrel{2008-2011}{2005-2006}$

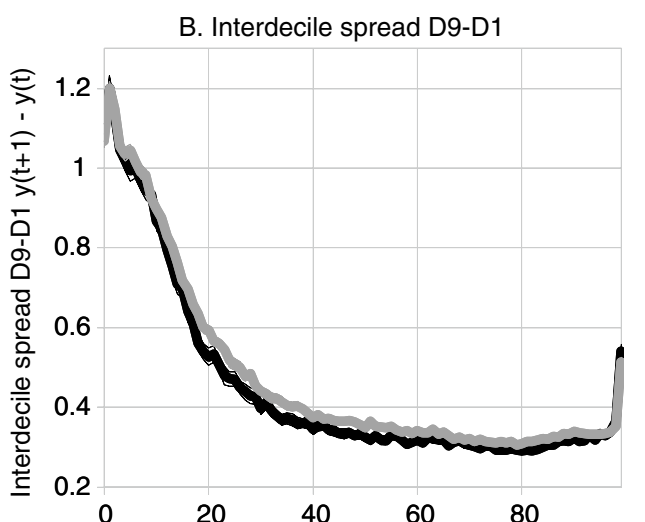

Rank in the distribution of past normalised wage income 2005-2006 2008-2011

D. Crow-Siddiqui Kurtosis

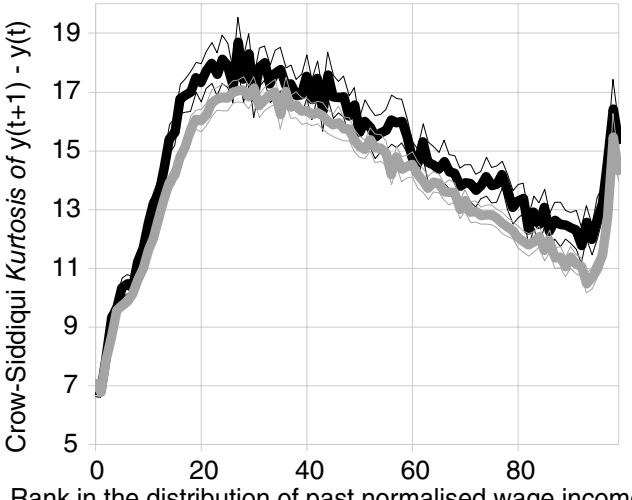

Rank in the distribution of past normalised wage income $\mathbf{2 0 0 5 - 2 0 0 6 \quad 2 0 0 8 - 2 0 1 1}$

Note: The lower and upper bounds of the confidence intervals at $95 \%$ are represented by thin lines. The confidence intervals are obtained by bootstrap (100 replications) (see box 2).

Reading note: At the 10th rank of the past wage scale, for the years 2005 and $2006,50 \%$ of the wage earners are confronted with yearly evolutions of normalised wage income lower than $1.3 \%$. For the years 2008 to 2011 , at the same level of the scale, $10 \%$ of the wage earners are confronted with evolutions lower than $0.2 \%$.

Coverage: Metropolitan France between 2005 and 2011, all wage earners except agricultural wage earners and apprentices and trainees, except wages directly paid by households.

Sources: Insee, "all wage earners" DADS Panel. 
of the crisis than over the preceding years. This is, however, not the case for the wage earners located at more intermediary positions.

The Crow-Siddiqui Kurtosis of the yearly variations of wage income decreases significantly over the crisis for a fraction of the wage earners, among the relatively low past wage incomes on the one hand, and for a fraction of the highest past wage incomes on the other hand (Figure III-D). For the wage earners located over other positions in the scale of past wage incomes, the data do not allow to conclude that there was a significant variation in the weight of the distribution tails over the course of the crisis. This shows that the slight increase in the magnitude of the uncertainty on future wage income over the crisis does not result chiefly from rare events.

These results highlight a slight increase of the dispersion of individual yearly evolutions of wage income over the course of the crisis, to the same extent in France as that estimated by Guvenen et al. (2014) for the US, and inconsistent with the very large increase documented by Storesletten et al. (2004). At the bottom and top ends of the past wage income scale, the downward asymmetry of the distribution of the yearly evolutions of wage income is accentuated over the course of the crisis: the very unfavourable evolutions are more frequent, and play a greater role in the individual dynamics of wage income than over the years before. It is, however, not the case at the intermediary ranks of the scale, in contrast with the American case for which this phenomenon concerns all wage earners (Guvenen et al., 2014). What is more, the magnitude of this phenomenon is also greater in the US than in France. Additionally, this variation of the dynamics of wage income over the crisis is not observed identically for all wage earners, and may depend on their human capital. Indeed, holding a higher education degree seems to have a protective effect on wage earners, especially for the highest-paid. However, the youngest wage earners seem to be less affected by the crisis than their elders (see the online complement $\mathrm{C} 1$ ).

\section{More unfavourable dynamics of working time for the lowest-paid wage earners, less advantageous wage evolutions for the highest-paid}

The yearly variations of wage income combine shocks regarding full-time equivalent wages (wage increase or reduction) and shocks regarding working time (job loss and unemployment). ${ }^{4}$ Over the course of the business cycle, the same shocks might not be predictive of the evolutions of wage income: in a good economic period, positive shocks on wages (rises and upwards mobility) and, in times of crisis, the volatility of working time - reflecting the risk of non-employment - can weigh differently on the dynamics of wage income. By overlooking the possible correlation between these shocks, we split wage income into full-time equivalent (FTE) wages and into working time, and we examine changes in the conditional distributions of the evolutions of full-time equivalent wages (cf. Box 2).

The evolutions of normalised wages are less favourable over the course of the crisis than during the years preceding it. This, however, does not concern in the same way the strongest and the weakest evolutions, nor the lowest-paid and highest-paid wage earners. With the notable exception of the lowest-paid wage earners, the first decile of the evolutions of normalised wages decreases significantly between 2005-2006 and 2008-2011 (Figure IV): the least favourable evolutions of wages worsened during the crisis. However, for the lowest-paid wage earners, these least favourable evolutions did not vary. This may attest to rigidities in the adjustment of wages at the lower end of the wage scale, linked to minimum wage and wage grids. These rigidities are less pronounced at the top end of the scale, where the variable part of pay, which can be very significant, is a source of flexibility. The median of the wage evolutions decreases over the whole wage income scale (Figure V-A). The drop is the most significant at both ends of the scale, and the smallest around the $80^{\text {th }}$ percentile of past normalised wage income. Finally, the last decile of the evolutions of wages, which corresponds to the most favourable evolutions, did not vary over the course of the crisis except for the highest-paid wage earners for whom it decreases significantly.

Consequently, except at the extremities of the scale, the dispersion of the evolutions of wages

\footnotetext{
4. The "all wage earners" DADS panel does not allow for the observation of individuals for as long as they have been in paid employment. Morevover, we focus on individuals who have received a wage income greater than $1 / 8$ of minimum wage between $\mathrm{t}-5$ and $\mathrm{t}+1$. However, it does allow for the observation of interruptions to paid employment which arise for example during year $t+1$, since we do not impose any restriction with regards to the number of days remunerated. Thus, we do not directly observe unemployment and inactivity, but a decline in working time between $t$ and $t+1$, especially if the number of days remunerated decreases, may be interpreted as a passing period of unemployment or inactivity. However, our method does not allow for the observation of long-lasting interruptions to paid employment, for example interruptions which might last the whole of year $t+1$.
} 
Figure IV

\section{Deciles of the individual evolutions of normalised FTE wages before and during the crisis}

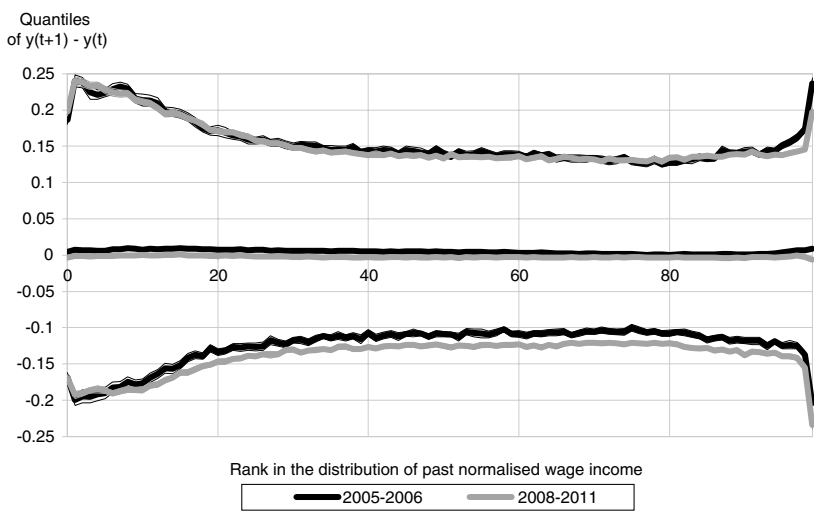

Note: The lower and upper bounds of the confidence intervals at $95 \%$ are represented by thin lines. The confidence intervals are obtained by bootstrap (100 replications) (see box 2). Only wage earners for whom a full-time equivalent work volume can be calculated are taken into account in this figure.

Reading note:At the 10th rank of the past wage scale, for the years 2005 and $2006,10 \%$ of the wage earners are confronted with yearly evolutions of normalised wage income lower than -0.11 in the logarithm. Reading note: at the 50 th rank of the past wage scale, for the years 2005 and 2006 , $10 \%$ of wage earners are confronted with yearly evolutions of normalised wage income lower than -0.11 in the logarithm.

Coverage: Metropolitan France between 2005 and 2011, all wage earners except agricultural wage earners and apprentices and trainees, except wages directly paid by households.

Sources: Insee, "all wage earners" DADS Panel.

Figure $\mathrm{V}$

Individual yearly evolutions of normalised FTE wages before and during the crisis
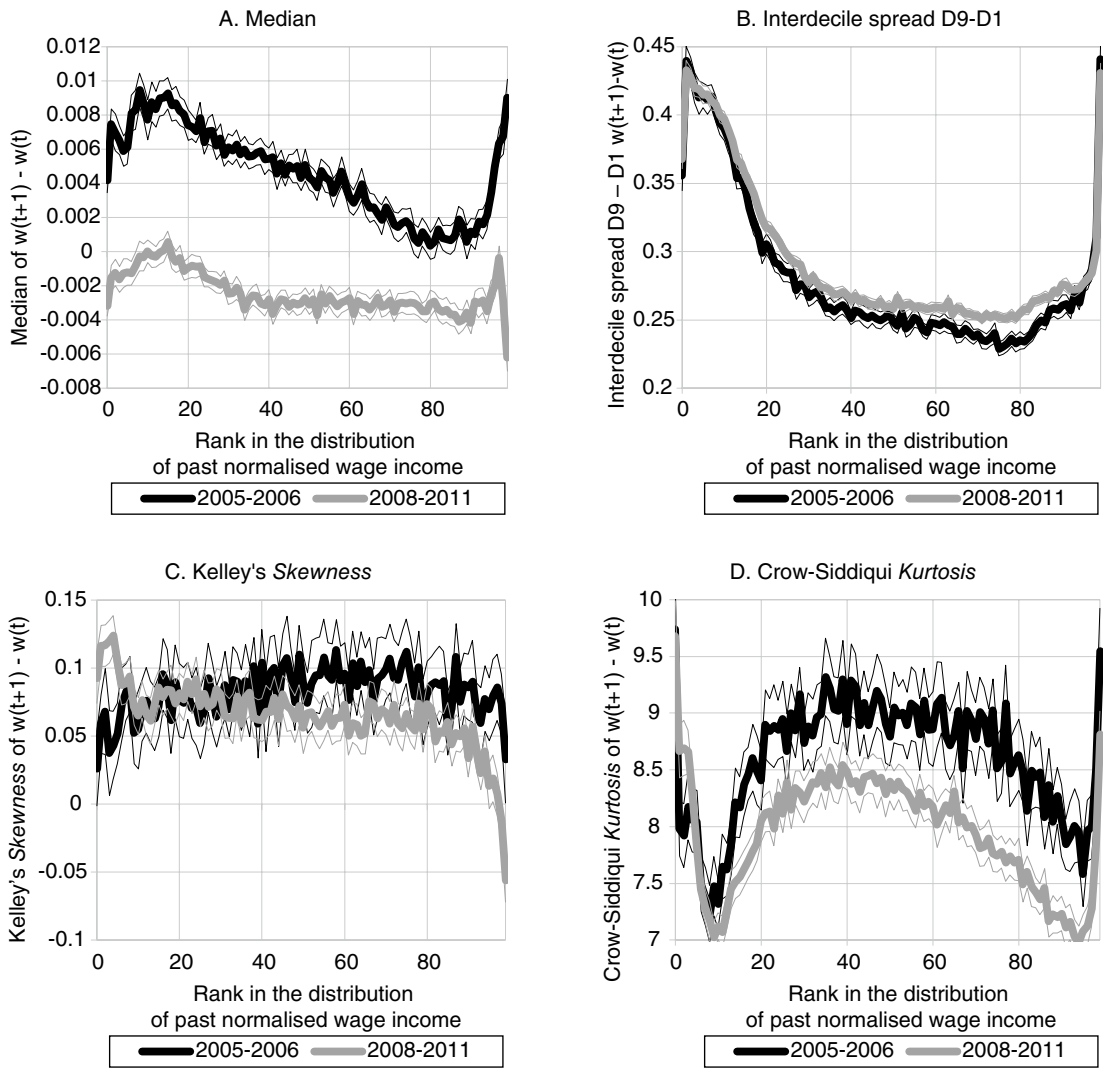

Note: The lower and upper bounds of the confidence intervals at $95 \%$ are represented by thin lines. The confidence intervals are obtained by bootstrap (100 replications) (see box 2). Only wage earners for whom a full-time equivalent work volume can be calculated are taken into account in this figure.

At the 10 th rank of the past wage scale, for the years 2005 and 2006,50\% of the wage earners are confronted with yearly evolutions of normalised wage income lower than $0.8 \%$. For the years 2008 to 2011 , at the same level of the scale, $50 \%$ of the wage earners are confronted with negative yearly evolutions (graph A).

Coverage: Metropolitan France between 2005 and 2011, all wage earners except agricultural wage earners and apprentices and trainees, except wages directly paid by households.

Sources: Insee, "all wage earners" DADS Panel. 
increases over the course of the crisis, because the most unfavourable evolutions get worse whereas the most favourable do not vary: the D9-D1 interdecile range increases significantly over a large part of the scale, from the $20^{\text {th }}$ to the $96^{\text {th }}$ percentile of past normalised wage income (Figure V-B) and remains constant for the wage earners located at the extremity of the scale. The drop in median evolutions over the crisis limits the increase in the weight of the least favourable evolutions in this dispersion. The asymmetry of this uncertainty, measured with Kelley's skewness, does not vary significantly over the course of the crisis for the largest part of wage earners (Figure V-C). For the lowest-paid wage earners, the drop in the median evolutions comes to constrict the lower end of the distribution of individual wage evolutions and extend the upper end. The weight of the favourable evolutions in the dispersion increases: Kelley's Measure of Skewness increases below the $8^{\text {th }}$ percentile of normalised wage income (Figure V-C). Finally, for the highest-paid wage earners, the drop in the most favourable evolutions and the least favourable evolutions is of a similar magnitude, and is larger than the drop in median evolutions: the dispersion does not increase, but the weight of the most favourable evolutions decreases whereas that of the least favourable evolutions increases. The downward asymmetry is accentuated: Kelley's Measure of Skewness decreases significantly between 2005-2006 and 2008-2011.

The weight of the distribution tails in the uncertainty on future wages, measured by Crow-Siddiqui Kurtosis, decreases over the course of the crisis for a large majority of wage earners, above the $14^{\text {th }}$ percentile of past normalised wage income (Figure V-D): at these levels of the wage income scale, the increase of the dispersion of the evolutions of wages over the course of the crisis reflects more an increase of the uncertainty perceptible to all the wage earners than an amplification of the relatively rare evolutions. However, even over the period 2008-2011, this weight remains much higher than that of the Gaussian reference. For the lowest-paid wage earners, it does not vary or it increases slightly. For the highest-paid wage earners, the variation of the individual dynamics of wage income therefore arise from a deformation of the distribution of the individual evolutions of FTE wage over the course of the crisis. However, for the lowest-paid wage earners, this variation is not found in the evolutions of wages and therefore corresponds to a change in the individual dynamics of working time. This can be confirmed by focusing specifically on the shocks of FTE working time (see the online complement C2). So, for the lowest-paid wage earners, the asymmetry towards the bottom end of the individual evolutions of FTE working time is accentuated during the crisis: the increased significance of the unfavourable evolutions in the individual dynamics of wage income results from an increased frequency of very negative evolutions of working time.

\section{Inter-firm mobility is more frequent but less uncertain over the course of the crisis, and the evolutions in a same company rarer and more dispersed}

The individual evolutions of wage income may differ significantly according to whether they are associated or not with a change of employer: payment practices may in fact be dissimilar from one employer to the next (Abowd et al., 1999). Furthermore, by participating in the improvement of matching employee with employer, the transitions from one employer to another explain a large part of wage progression over the course of the professional life cycle (Topel \& Ward, 1992). In the US, the evolutions of earned income associated with mobility are much more dispersed than those faced wage earners who do not change employer (Guvenen et al., 2016). The slight increase in the dispersion of individual evolutions of wage income measured over the course of the crisis could therefore result from more frequents changes of employers. We distinguish between the evolutions of wage income, of wages and of working time according to wage earners behaviour on the labour market, namely the evolutions seen by the wage earners who stay in the same firm between $t$ and $t+1$ from those of the wage earners who change companies (see Box 2).

Inter-company moves are more frequent for the lowest-paid workers (Figure VI): the frequency of inter-firm moves is higher than $15 \%$ among the $10 \%$ lowest-paid wage earners, and lower than $10 \%$ for the $70 \%$ highest-paid. At all levels of past wage income, they are more common during the crisis, particularly in the upper half of the distribution of past wage income.

These results must however be taken with precaution: changes of employer may occur for different reasons - for example in the case of liquidation of a company - and the data do not distinguish between forced moves and chosen 
moves. Furthermore, the choice to change company and the position occupied after this change depend on the wage earner's expected future wage income, and therefore the uncertainty that we seek to evaluate.
The crisis weighs above all on the most favourable moves, and to a lesser extent on the least favourable evolutions in a same company (Figure VII). So, however considerable its size, the increase of the first decile of the evolutions

\section{Figure VI \\ Frequency of inter-company moves before and during the crisis}

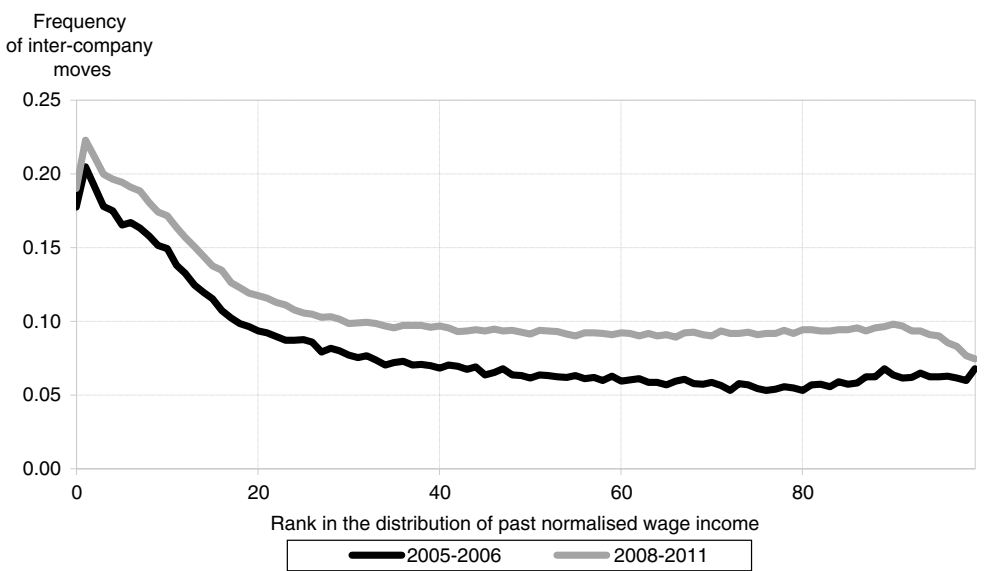

Note: Mobile wage earners are defined as those whose main employer (defined by the SIREN [French company number] and the one associated with the largest number of remunerated days of work in the year) changes between $t$ and $t+1$ (cf. box 2).

Reading note: at the 10 th rank of the past wage scale, for the years 2005 and 2006, $15 \%$ of the wage earners change main employer between $t$ and $t+1$. For the years 2008 to 2011 and at the same rank of the scale, they make up $17 \%$.

Coverage: Metropolitan France between 2005 and 2011, all wage earners except agricultural wage earners and apprentices and trainees, except wages directly paid by households.

Sources: Insee, "all wage earners" DADS Panel

Figure VII

\section{Deciles of the individual evolutions of normalised wage income according to the mobility of the wage} earners before and after the crisis.
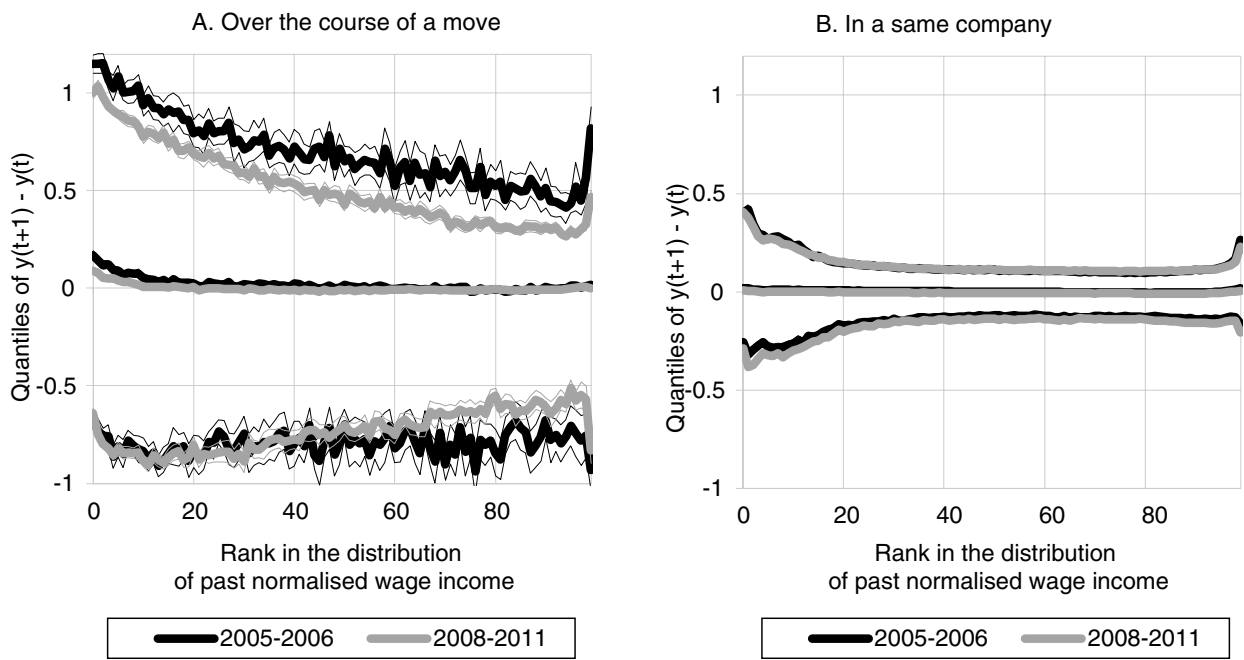

Note: Mobile wage earners are defined as those whose main employer (defined by the SIREN [French company number]) and the one associated with the largest number of remunerated days of work in the year) changes between $t$ and $t+1$. Immobile wage earners are defined as those who work under one sole employer in $t$ and $t+1$. The lower and upper bounds of the confidence intervals at $95 \%$ are represented by thin lines. The confidence intervals are estimated by bootstrap (100 replications) (see box 2 ).

Reading note: At the 10th rank of the past wage scale, for the years 2005 and $2006,10 \%$ of the wage earners are confronted with yearly evolutions of normalised wage income lower than -0.84 in the logarithm. For the years 2008 to 2011 , at the same level of the scale, $10 \%$ of the wage earners are confronted with evolutions lower than -0.55 in the logarithm.

Coverage: Metropolitan France between 2005 and 2011, all relatively stable wage earners in paid employment, except wages directly paid by households.

Sources: Insee, "all wage earners" DADS Panel 
Figure VIII

Individual yearly evolutions of normalised wage income according to mobility of the wage earners before and after the crisis

A. Median

a. Over the course of a move


C. Kelley's Skewness

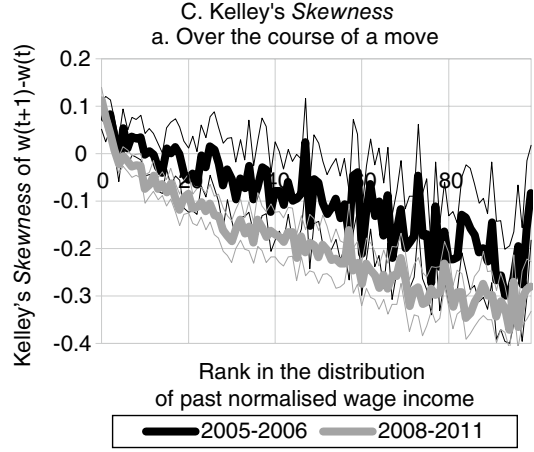

D. Crow-Siddiqui Kurtosis a. Over the course of a move

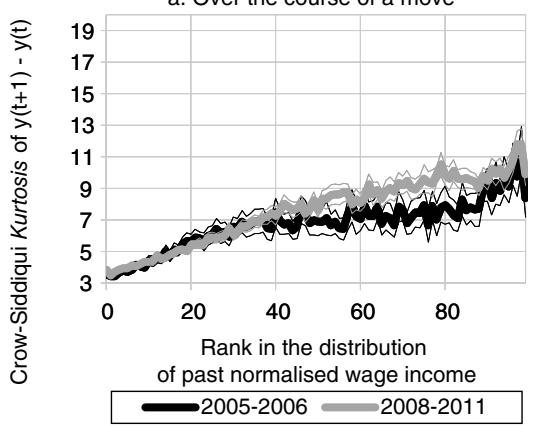

A. Median

b. In a same company
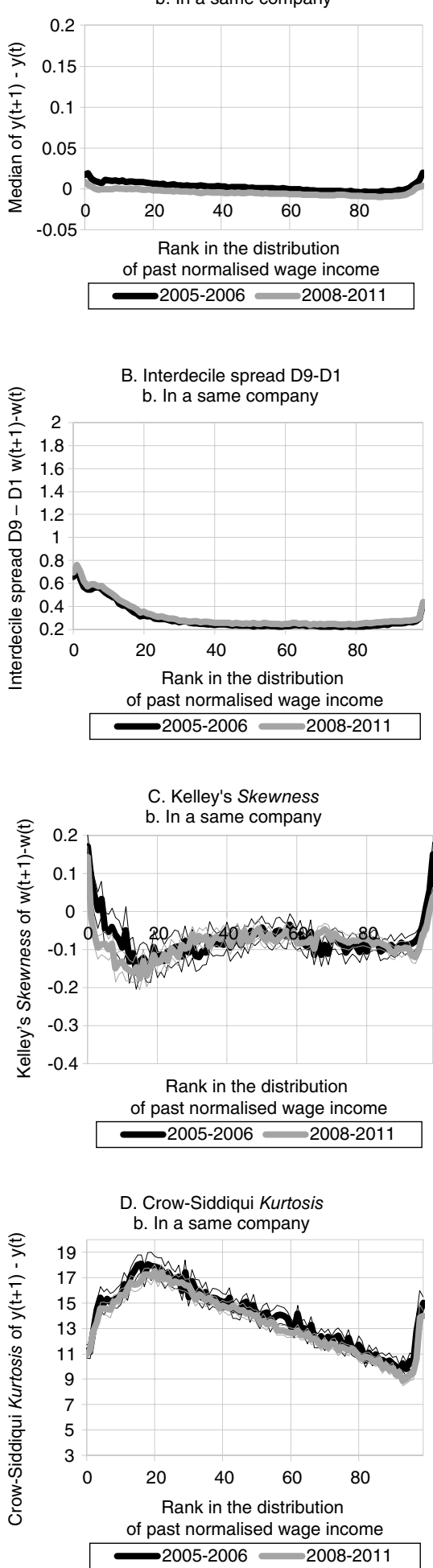

Note: Mobile wage earners are defined as those whose main employer (defined by the SIREN [French company number]) and the one associated with the largest number of remunerated days of work in the year) changes between $t$ and $t+1$. Immobile wage earners are defined as those who work under one sole employer in $t$ and $t+1$. The lower and upper bounds of the confidence intervals at $95 \%$ are represented by thin lines. The confidence intervals are estimated by bootstrap (100 replications) (see box 2 ).

Reading note: At the 10th rank of the past wage scale, for the years 2005 and $2006,50 \%$ of the wage earners who change employer are confronted with yearly evolutions of normalised wage income lower than 55 . For the years 2008 to 2011 , at the same level of the scale, $10 \%$ of the wage earners who change employer are confronted with evolutions lower than $0.7 \%$ (graph A).

Coverage: Metropolitan France between 2005 and 2011, all wage earners except agricultural wage earners and apprentices and trainees, except wages directly paid by households.

Sources: Insee, "all wage earners" DADS Panel. 
associated with mobility is not significant, except for a few points at the top of the wage income scale (Figure VII-A). However, over almost all of the wage income scale, the first decile of the individual yearly variations of normalised wage income in a same company decreases very slightly but in a significant way (Figure VII-B). Conversely, the last decile of the evolutions in a same company does not vary over the course of the crisis, except at the top of the wage income scale where it decreases (Figure VII-B), whereas the last decile of the evolutions of normalised wage income associated with mobility decreases greatly over the whole wage income scale, except perhaps at a few points (Figure VII-A). The median of the variations of wage income over the course of moves between companies decreases over the course of the crisis over nearly the whole lower half of the wage income scale (Figure VIII-A.a). Throughout the scale, the median of the evolutions of normalised wage income in a same company also decreases (Figure VIII-A.b), but over the lower half of the scale this drop is much smaller than for mobile wage earners. Finally, the dispersion of the evolutions over the course of a move between companies (Figure VIII-B.a) is always much greater than that of the evolutions of a same company (Figure VIII-B.b).

Since the first decile of the evolutions of wage income over the course of a move between companies does not vary, or increases over the course of the crisis, whereas the last decile decreases, the magnitude of the uncertainty associated with mobility, in the sense of the dispersion of the individual evolutions of the wage earners who change employer, decreases over the course of the crisis (Figure VIII-B.a). Contrastingly, the variations of the first and last deciles of the evolutions of wage income in a same company are small, so that, for wage earners who do not change company, the extent of the uncertainty on future wage income barely increases between 2005-2006 and 2008-2011 (Figure VIII-B.b). The variations of the extent of the uncertainty over the course of the crisis are therefore much greater for mobile wage earners than for immobile wage earners. The asymmetry of individual yearly evolutions of wage income according to mobility does not vary over the course of the crisis, except for the wage earners at the lower end of the wage income scale who do not change employer, for whom Kelley's Measure of Skewness decreases (Figure VIII-C). The weight of the distribution tails increases for the variations over the course of inter-firm moves for the wage earners from the intermediary to higher ranks of the distribution of past wage income, but it does not vary for the others (Figure VIII-D). For these mobile wage earners in the middle of the wage income scale, the drop in the dispersion of the evolutions of wage income over the course of the crisis concerns the most frequent progressions more than rare events. Wage dynamics, for the wage earners in the upper half of the scale, and working time dynamics for all the wage earners, both contribute to these variations (see the online complement $\mathrm{C} 2$ ).

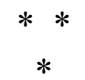

This article is a first application over French data of the original non-parametric method proposed by Guvenen et al. (2016). In contrast with most works on individual dynamics of wage income and wage, this method does not rely on a hypothesis of conditional log-normality, and therefore allows for focusing on the asymmetry and weight of rare events in these dynamics, and on their variation over the course of the crisis of 2008.

For the individuals who are relatively stable in paid employment analysed in this article, the individual dynamics of wage income are less favourable over the course of the crisis than over the years before. The greatest variations with the crisis concern first and foremost the lowest-paid wage earners in the past, and to a lesser extent the very high wage incomes, which may contribute to a rise in wage income inequalities measured over a cross-section. The dynamics of wage income are also slightly more uncertain between 2008 and 2012 than between 2005 and 2007, which also tends to exacerbate inequalities.

Over the course of the crisis, these are the least favourable individual evolutions of wage income and, to a lesser extent the most favourable - and only for the highest and lowest-paid wage earners in the past - which decrease the most. For these wage earners located at the top and bottom of the distribution of past wage income, these most and least favourable evolutions decrease faster than the median evolutions, such that the weight of the least favourable evolutions in the uncertainty on future wage income increases. Consequently, the shape of this uncertainty varies over the course of the crisis: the distribution 
of the evolutions of wage income is more downwardly asymmetrical than over the course of the years before. In other words, the relative significance of the very unfavourable evolutions in the individual dynamics of wage income is accentuated over the course of the crisis, for the low past wage incomes on the one hand and the high past wage incomes on the other. This phenomenon is however of a smaller magnitude than that documented by Guvenen et al. (2014) for the United States, and does not concern all of the wage earners. This difference could result from disparities in behaviour between French and American wage earners and employers, but also from differences in the institutions which frame the labour market: the inequalities of wage income and of wages are actually greater in the US than in France, and the unemployment rate is smaller in the US over the period which precedes the crisis. The weight of rare events, finally, decreases slightly or does not vary during the crisis, in both France and the US: the variations of the distribution of the individual evolutions of wage income therefore result from relatively common evolutions rather than from extreme and rare shocks.

At the bottom of the distribution, these variations over the course of the crisis result above all from variations in the dynamics of working time, whereas for the highest-paid wage earners the weight of wages is greater. To the extent that, for the lower end of the distribution of past wage incomes, this major role of the dynamics of working time may reflect a risk of job loss, our approach could be widened by taking into account unemployment benefits. This would perhaps allow for a more complete overview of income dynamics linked to presence on the labour market.

Wage earners mobility, finally, contributes to the variation of the wage income dynamics during the crisis. In fact, changing employer is more frequent over the course of the crisis than during the years before. The evolutions of wage income associated with mobility are always more uncertain than those of the wage earners who stay in a same company. This increased frequency of inter-firm moves therefore contributes to the increase of the uncertainty on wage income highlighted over all of the wage earners. However, the uncertainty associated with changes of employer decreases over the course of the crisis, which comes to moderate this effect. To the extent that we do not distinguish between forced moves - for example due to the closing of a company - and chosen moves, this evolution, which results from both working time and wages, remains difficult to interpret.

\section{BIBLIOGRAPHY}

Abowd, J. M., Kramarz, F. \& Margolis, D. N. (1999). High Wage Workers and High Wage Firms. Econometrica, 67(2), 251-333.

Altonji, J. G., Smith, A. A. \& Vidangos, I. (2013). Modeling earnings dynamics. Econometrica, 81(4), $1395-1454$.

Arellano M., Blundell, R. \& Bonhomme, S. (2017). Earnings and consumption dynamics: a nonlinear panel data framework. Econometrica, 85(3), 693-734.

Ayllón, S. \& Ramos, X. (2015). Permanent and transitory earnings inequality of young people in Europe. Negotiate Working paper D4.1.

Baker, M. \& Solon, G. (2003). Earnings Dynamics and Inequality among Canadian Men, 1976-1992: Evidence from Longitudinal Income Tax Record. Journal of Labor Economics, 21(2), 289-321.
Blundell, R. \& Preston I. (1998). Consumption inequality and income uncertainty. The Quarterly Journal of Economics, 113(2), 603-640.

Bonhomme, S. \& Robin, J.-M. (2009). Assessing the Equalizing Force of Mobility Using Short Panels: France, 1990-2000. The Review of Economic Studies, 76(1), 63-92.

Britton, J., Shephard, N. \& Vignoles, A. (2015). Comparing sample survey measures of English earnings of graduates with administrative data during the Great Recession. IFS, Working Paper W15/28.

https://www.ifs.org.uk/uploads/publications/wps/ WP201528.pdf

Cappellari, L. (2004). The Dynamics and Inequality of Italian Men's Earnings: Long-Term Changes or Transitory Fluctuations? The Journal of Human Resources, 39(2), 475-499. 
Ceci-Renaud, N., Charnoz P. \& Gaini M. (2014). Évolutions de la volatilité des revenus salariaux du secteur privé en France depuis 1968. Insee, Document de travail $\mathrm{N}^{\circ} \mathrm{G} 2014 / 03$.

https://www.insee.fr/fr/statistiques/1381039

Constantinides, G. M. \& Duffie, D. (1996). Asset Pricing with Heterogeneous Consumers. Journal of Political Economy, 104(2), 219-40.

Coudin E., Marc B., Pora, P. \& Wilner, L. (2014). La baisse des inégalités de revenu salarial marque une pause pendant la crise. In : France, portrait social 2014, pp. 55-65. Paris : Insee.

https://www.insee.fr/fr/statistiques/1288514?sommaire= 1288529

Crow, E. L \& Siddiqui, M. M. (1967). Robust Estimation of Location. Journal of the American Statistical Association, 62(318), 353-389.

Cunha, F. \& Heckman, J. J. (2007). The Evolution of Inequality, Heterogeneity and Uncertainty in Labor Earnings in the U.S. Economy. NBER, Working Paper $\mathrm{N}^{\circ} 13526$.

Dynan, K., Elmendorf, D. \& Sichel, D. (2012). The Evolution of Household Income Volatility. The B.E. Journal of Economic Analysis and Policy, 12(2), 1-42.

Flodén, M. (2006). Labour Supply and Saving under Uncertainty. The Economic Journal, 116(513), 721-737.

Gottschalk, P., Moffitt, R., Katz, L. F. \& Dickens, W. T. (1994). The Growth of Earnings Instability in the U.S. Labor Market. Brooking Papers on Economic Activity, 1994(2), 212-272.

Guvenen, F., Karahan, F., Ozkan, S. \& Song, J. (2016). What do data on millions of US workers reveal about life-cycle earnings risk? mimeo.

https://guvenendotcom.files.wordpress.com/2014/ 04/gkos_2016_rev2_v47.pdf

Guvenen, F., Ozkan, S. \& Song, J. (2014). The Nature of Countercyclical Income Risk. Journal of Political Economy, 122(3), 621-660.
Haider, S. J. (2001). Earnings Instability and Earnings Inequality of Males in the United States: 1967-1991. Journal of Labor Economics, 19(4), 799-836.

Kelley, T. L. (1947). Fundamentals of Statistics. Cambridge: Harvard University Press.

Low, H., Meghir, C. \& Pistaferri, L. (2010). Wage Risk and Employment Risk over the Life Cycle. The American Economic Review, 100(4), 1432-1467.

Magnac, T., Pistolesi, N. \& Roux, S. (2017). Human capital investment and the lifecycle of earnings. Journal of Political Economy, forthcoming.

Mankiw, N. G. (1986). The Equity Premium and the Concentration of Aggregate Shock. Journal of Financial Economics, 17, 211-219.

Moffitt, R. A. \& Gottschalk, P. (2002). Trends in the transitory variance of earnings in the United States. The Economic Journal, 112.478, C68-C73.

Moffitt, R. A. \& Gottschalk, P. (2011). Trends in the covariance structure of earnings in the US: 1969-1987. The Journal of Economic Inequality, 9(3), 439-459.

Piketty, T. (2013). Le capital au XXI" siècle. Paris : Seuil.

Pistolesi, N. (2014). Income and Consumption Risk: Evidence from France. Annals of Economics and Statistics, 113, 347-377.

Ramos, X. (2003). The Covariance Structure of Earnings in Great Britain, 1991-1999. Economica, 70(278), 353-374.

Salgado, S., Guvenen, F. \& Bloom, N. (2016). Skewed Business Cycles. mimeo. https://fguvenendotcom.files.wordpress.com/2014/ 04/sgb_firm_skew_2016_ss_v1_edited.pdf

Storesletten, K., Telmer, C. I. \& Yaron, A. (2004). Cyclical Dynamics in Idiosyncratic Labor Market Risk. Journal of Political Economy, 112(3), 695-717.

Topel, R. H. \& Ward, M. P. (1992). Job Mobility and the Careers of Young Men. The Quarterly Journal of Economics 107(2), 439-479. 


\section{DESCRIPTIVE STATISTICS}

Table A1-I

Number of observations, share of women, division by age brackets, wage income and wages

\begin{tabular}{|c|c|c|c|c|c|c|c|c|c|}
\hline & \multirow[b]{2}{*}{ Period } & \multirow{2}{*}{$\begin{array}{c}\text { Number of } \\
\text { observations } \\
\text { accumulated } \\
\text { over the period? }\end{array}$} & \multirow[b]{2}{*}{$\begin{array}{c}\text { Share of } \\
\text { women } \\
\text { (in } \% \text { ) }\end{array}$} & \multicolumn{4}{|c|}{ Share of age brackets (in \%) } & \multirow{2}{*}{$\begin{array}{c}\text { Logarithm of } \\
\text { average wage } \\
\text { income (standard } \\
\text { deviation) }\end{array}$} & \multirow{2}{*}{$\begin{array}{c}\text { Logarithm of } \\
\text { average FTP } \\
\text { wage (standard } \\
\text { deviation) }\end{array}$} \\
\hline & & & & $\begin{array}{l}23-29 \\
\text { years } \\
\text { old }\end{array}$ & $\begin{array}{l}30-39 \\
\text { years } \\
\text { old }\end{array}$ & $\begin{array}{l}40-49 \\
\text { years } \\
\text { old }\end{array}$ & $\begin{array}{l}50-59 \\
\text { years } \\
\text { old }\end{array}$ & & \\
\hline \multirow{2}{*}{ Initial sample } & $2005-2006$ & $5,811,551$ & 47.4 & 26.1 & 27.3 & 26.3 & 20.3 & $9.50(1.15)$ & $10.0(0.46)$ \\
\hline & 2008-2011 & $10,196,836$ & 48.2 & 26.2 & 26.3 & 26.4 & 21.2 & $9.50(1.16)$ & $10.0(0.46)$ \\
\hline \multirow{2}{*}{$\begin{array}{l}\text { Censoring at } 1 / 8 \\
\text { of minimum wage }\end{array}$} & 2005-2006 & $5,426,296$ & 46.7 & 24.6 & 27.7 & 26.9 & 20.7 & $9.71(0.75)$ & $10.0(0.45)$ \\
\hline & $2008-2011$ & $9,554,635$ & 47.7 & 24.5 & 26.7 & 27.1 & 21.7 & $9.72(0.75)$ & $10.0(0.45)$ \\
\hline \multirow{2}{*}{$\begin{array}{l}\text { Relatively stable } \\
\text { wage earners } \\
\text { in paid employment }\end{array}$} & 2005-2006 & $3,778,227$ & 45.9 & 16.0 & 29.8 & 30.7 & 23.3 & $9.93(0.58)$ & $10.1(0.44)$ \\
\hline & $2008-2011$ & $5,742,026$ & 47.1 & 16.2 & 28.9 & 30.6 & 24.3 & $9.93(0.59)$ & $10.1(0.43)$ \\
\hline
\end{tabular}

Coverage: Metropolitan France between 2005 and 2011, all wage earners except agricultural wage earners and apprentices and trainees, except wages directly paid by households.

Sources: Insee, "all wage earners" DADS Panel.

Table A1-II

Division of the sample by business sector, professional categories and degree level

\begin{tabular}{|c|c|c|c|c|c|c|c|c|c|}
\hline & \multirow[b]{2}{*}{ Period } & \multirow{2}{*}{$\begin{array}{c}\text { Share of wage } \\
\text { earners in the } \\
\text { private sector } \\
\text { (in \%) }\end{array}$} & \multicolumn{4}{|c|}{ Division into socioprofessional categories (in \%) } & \multicolumn{3}{|c|}{ Division of degree level (in \%) } \\
\hline & & & $\begin{array}{c}\text { Execu- } \\
\text { tives }\end{array}$ & $\begin{array}{l}\text { Intermediary } \\
\text { professions }\end{array}$ & Employees & Labourers & $\begin{array}{c}\text { Lower than } \\
\text { baccalaureate } \\
\text { (bac) }\end{array}$ & $\begin{array}{l}\text { Bac to } \\
\text { bac+2 }\end{array}$ & $\begin{array}{l}\mathrm{Bac}+3 \\
\text { and more }\end{array}$ \\
\hline \multirow{2}{*}{ Initial sample } & 2005-2006 & 77.4 & 15.4 & 23.9 & 32.0 & 28.7 & 51.2 & 34.4 & 14.4 \\
\hline & 2008-2011 & 77.9 & 15.7 & 21.1 & 34.6 & 28.2 & 49.4 & 35.9 & 14.7 \\
\hline \multirow{2}{*}{$\begin{array}{l}\text { Censoring at } 1 / 8 \\
\text { of minimum wage }\end{array}$} & 2005-2006 & 76.9 & 16.0 & 24.6 & 31.3 & 28.2 & 50.9 & 34.6 & 14.5 \\
\hline & 2008-2011 & 77.5 & 16.4 & 21.7 & 33.8 & 27.8 & 48.8 & 36.1 & 15.0 \\
\hline \multirow{2}{*}{$\begin{array}{l}\text { Relatively stable } \\
\text { wage earners } \\
\text { in paid employment }\end{array}$} & 2005-2006 & 74.8 & 18.4 & 26.4 & 28.4 & 26.5 & 50.5 & 34.5 & 15.1 \\
\hline & 2008-2011 & 75.8 & 18.3 & 24.0 & 31.2 & 26.2 & 47.9 & 36.4 & 15.8 \\
\hline
\end{tabular}

Note: The naming of the socioprofessional categories used in these annual declarations of social data changed between 2008 and 2009 , causing a break in the trend including on the socioprofessional category with one figure. To the extent that we do not use the socioprofessional category in our analysis of the evolutions of wage income, this break does not pose a problem for the method used. The main point is to show that the selection made by the study of relatively stable wage earners does not differ substantially between 2005-2006 and 2008-2011. Wage-earning heads of companies are grouped together with the executives.

Coverage: Metropolitan France between 2005 and 2011, all wage earners except agricultural wage earners and apprentices and trainees, except wages directly paid by households.

Source: Insee, "all wage earners" DADS Panel. 
